\title{
Breastfeeding practices in a cohort of inner-city women: the role of contraindications
}

\author{
Lucinda England*1, Ruth Brenner ${ }^{1}$, Brinda Bhaskar ${ }^{2}$, Bruce Simons-Morton ${ }^{1}$, \\ Abhik Das ${ }^{2}$, Mary Revenis ${ }^{3}$, Nitin Mehta ${ }^{4}$ and John Clemens ${ }^{5}$
}

\begin{abstract}
Address: ${ }^{1}$ Division of Epidemiology, Statistics, and Prevention Research, National Institute of Child Health and Human Development, Department of Health and Human Services, Bethesda, MD 20895, USA, ${ }^{2}$ The Research Triangle Institute, Rockville, MD, 20852, USA, ${ }^{3}$ The Department of Neonatology, Children's National Medical Center, Washington, DC, 20010, USA, ${ }^{4}$ The Division of Neonatology, Georgetown University Hospital, Washington, DC, 20007, USA and ${ }^{5}$ The International Vaccine Institute, Seoul, Korea
\end{abstract}

Email: Lucinda England* - lbe9@cdc.gov; Ruth Brenner - brennerr@mail.nih.gov; Brinda Bhaskar - bbhaskar@rti.org; Bruce SimonsMorton - mortonb@mail.nih.gov; Abhik Das - adas@rti.org; Mary Revenis - mrevenis@cnmc.org; Nitin Mehta - mehtan@gunet.georgetown.edu; John Clemens - jclemens@ivi.int

* Corresponding author

Published: 20 August 2003

Received: 02 April 2003

BMC Public Health 2003, 3:28

Accepted: 20 August 2003

This article is available from: http://www.biomedcentral.com/147I-2458/3/28

(C) 2003 England et al; licensee BioMed Central Ltd. This is an Open Access article: verbatim copying and redistribution of this article are permitted in all media for any purpose, provided this notice is preserved along with the article's original URL.

\begin{abstract}
Background: Little is known about the role of breastfeeding contraindications in breastfeeding practices. Our objectives were to I) identify predictors of breastfeeding initiation and duration among a cohort of predominately low-income, inner-city women, and 2) evaluate the contribution of breastfeeding contraindications to breastfeeding practices.
\end{abstract}

Methods: Mother-infant dyads were systematically selected from 3 District of Columbia hospitals between 1995 and 1996. Breastfeeding contraindications and potential predictors of breastfeeding practices were identified through medical record reviews and interviews conducted after delivery (baseline). Interviews were conducted at 3-7 months postpartum and again at 7-12 months postpartum to determine breastfeeding initiation rates and duration. Multivariable logistic regression analysis was used to identify baseline factors associated with initiation of breastfeeding. Cox proportional hazards models were generated to identify baseline factors associated with duration of breastfeeding.

Results: Of 393 study participants, 201 (5I\%) initiated breastfeeding. A total of 61 women (16\%) had at lease one documented contraindication to breastfeeding; $94 \%$ of these had a history of HIV infection and/or cocaine use. Of the 332 women with no documented contraindications, 58\% initiated breastfeeding, vs. $13 \%$ of women with a contraindication. In adjusted analysis, factors most strongly associated with breastfeeding initiation were presence of a contraindication (adjusted odds ratio [AOR], 0.19; 95\% confidence interval [Cl], 0.08-0.47), and mother foreign-born (AOR, 4.90; $95 \% \mathrm{Cl}, 2.38-10.10)$. Twenty-five percent of study participants who did not initiate breastfeeding cited concern about passing dangerous things to their infants through breast milk. Factors associated with discontinuation of breastfeeding (all protective) included mother foreign-born (hazard ratio [HR], 0.55; 95\% Cl 0.39-0.77) increasing maternal age (HR for 5-year increments, $0.80 ; 95 \% \mathrm{Cl}, 0.69-0.92)$, and infant birth weight $\geq 2500$ grams (HR, $0.45 ; 95 \% \mathrm{Cl}, 0.26-0.80)$.

Conclusions: Breastfeeding initiation rates and duration were suboptimal in this inner-city population. Many women who did not breastfeed had contraindications and/or were concerned about passing dangerous things to their infants through breast milk. It is important to consider the prevalence of contraindications to breastfeeding when evaluating breastfeeding practices in highrisk communities. 


\section{Background}

Infants who are not breastfed experience increased morbidity from a variety of conditions compared with infants who are breastfed [1-9]. The American Academy of Pediatrics Work Group on Breastfeeding recommends that infants be exclusively breastfed for the first 6 months of life [10] and Healthy People 2010 includes a goal that $75 \%$ of women breastfeed in the early postpartum period [11]. In the United States, however, breastfeeding rates are below this goal, particularly among low-income and African American populations [12-14].

Despite the known benefits of breastfeeding, infant feeding guidelines in the United States do not include recommendations for universal breastfeeding [15-17]. For example, HIV infection and the use of certain medications and illicit drugs are considered to be contraindications to breastfeeding. Little is known, however, about the extent to which contraindications to breastfeeding contribute to breastfeeding rates.

We studied breastfeeding patterns in a population of predominately low-income, inner-city women who were interviewed shortly after delivery and at 2 additional times over the following 12 months. Specifically, we evaluated initiation rates and duration of breastfeeding, and explored maternal and infant factors associated with these outcomes. In addition, we explored reasons why women did not initiate breastfeeding, and why women stopped breastfeeding. In these analyses, we included an examination of the contribution of breastfeeding contraindications to breastfeeding practices.

\section{Methods}

Data for the current analysis of breastfeeding behaviors were obtained from a broader study that addressed a number of child health issues, including breastfeeding, but that had a primary focus on infant immunizations. Detailed study methods have been reported previously [18]. This study was approved by the institutional review boards of all participating study sites and collaborating institutions, and all women gave informed consent.

\section{Study sample}

Mothers of singleton infants were recruited shortly after delivery from 3 hospitals in the District of Columbia between August, 1995 and September, 1996. Two of the selected hospitals had a high prevalence of low-income patients, and enrollment at the third site was limited to nonprivate patients (patients cared for by staff physicians) to capture a sample of low-income, inner-city patients. Recruitment days were chosen systematically to ensure a representative sample of weekend and midweek sample days. Sampling was for a 24 -hour period on the selected days.

\section{Interviews}

Baseline interviews were conducted after delivery, usually during the postpartum hospital stay. Of the 452 baseline interviews, $417(92 \%)$ were conducted in the hospital during the postpartum stay, and 94\% were conducted within 2 days of delivery. All but 1 were completed within 2 weeks of delivery. Baseline interviews were conducted by trained research assistants and included a face-to-face interview and a short self-administered questionnaire. The face-to-face interview included questions about sociodemographic and psychological factors, including race, ethnicity, social support and health behaviors. The selfadministered questionnaire included questions about potentially sensitive topics such as wantedness of the pregnancy, and household drug and alcohol abuse. Follow-up interviews were conducted when infants were 3-7 months of age and again when infants were 7-12 months of age. Of 780 follow-up interviews, $89 \%$ were face-toface, and most were conducted in the mother's home.

At the 3-7 month follow-up interview, mothers were asked if they were currently breastfeeding, bottle feeding, or both. Women who were only bottle feeding were asked if they had ever breastfed their infant, and if so, for how many weeks or months. It was assumed that bottle feeding was interpreted by mothers to mean "formula" feeding or "milk" feeding and not the feeding of expressed breast milk by bottle. Mothers who answered that they had never breastfed their infants were asked why they chose not to breastfeed; mothers who had stopped breast feeding were asked to identify the reasons why they stopped. Choices were derived from the pretest for the 1995 National Survey of Family Growth [19] and included "I was ill/weak," "baby was ill/weak," "Nipple and/or breast problems (e.g., pain, dryness)," "I produced insufficient milk," "Schedule difficult (e.g. my job or baby's eating schedule)," "Baby refused," "I didn't want to pass dangerous things through breast milk (e.g., medications, cigarette smoke, alcohol, drugs)," "I was never taught or didn't know how," "I didn't want to," or "Other reason." Women were allowed to select as many choices as applied.

At the 7-12 month follow-up interview, mothers were asked again if they were currently breastfeeding, bottle feeding, or both. Mothers who had quit breastfeeding were asked why they stopped, using the same selection of reasons as previously described.

\section{Medical record reviews}

Information abstracted from maternal medical records included parity; type of delivery; gestational age at delivery; use of medications at the time of admission for delivery, use of alcohol, tobacco, or drugs of abuse during pregnancy; presence of selected medical conditions during pregnancy (including HIV/AIDS); and discharge ICD9 
codes. Information abstracted from infant medical records included infant birth weight, sex, and discharge ICD9 codes.

\section{Contraindications to breastfeeding}

The definition of a documented contraindication to breastfeeding was based on a review of recent literature addressing contraindications to breastfeeding for North American women [15-17] and included one or more of the following: maternal HIV infection, active tuberculosis infection, or infection with human T-cell lymphotropic virus type I or type II; illicit drug abuse/drug dependence (opioids, cocaine, amphetamines, barbiturates, and hallucinogens); or maternal use of certain medications (radiopharmaceuticals at therapeutic doses, chloramphenicol, bromocriptine, cyclosporin, methadone, cyclophosphamide, doxorubicin, ergotamine, lithium, methotrexate, phenorbarbital, and phenindione). Women with contraindications were identified in the following manner. Maternal medical records were reviewed for use of the medications listed above. Maternal discharge ICD9 codes were searched for documentation of active tuberculosis (ICD9 codes 010-018) and human T-cell lymphotrophic virus (ICD9 codes 079.51 and 079.52). Maternal medical records and discharge ICD9 codes were searched for documentation of HIV/AIDS (ICD9 code 042 or V08), and drug abuse/drug dependence (ICD9 codes 304.0-304.2, 304.4-304.9, 305.1-305.3-305.7, 648.30, 760.71$760.73,760.75)$. It was assumed that women with ICD9 codes for unspecified drug dependence $(304.8,304.9$, and 648.30) were using drugs included in the list of breastfeeding contraindications. Infant discharge ICD9 codes were reviewed for documentation of infant drug withdrawal (ICD9 code 779.5). Women with evidence of any breastfeeding contraindication from any source were considered to have a "documented" contraindication to breastfeeding. Women who reported in follow-up interviews that they did not initiate breastfeeding because they "didn't want to pass dangerous things" but who had no documentation of a contraindication were considered to have a "perceived" contraindication to breastfeeding. Women responding that they "didn't want to pass dangerous things" were not asked to name the substance or infection about which they were concerned, so it is unknown how many women with perceived contraindications had otherwise unidentified true contraindications.

\section{Duration of breastfeeding}

Duration of breastfeeding was based on the number of weeks or months mothers reported breastfeeding at the 37 month interview (for those women who had quit before the 3-7 month follow-up interview) or at the 7-12 month interview (for those still breastfeeding at the time of the 3-7 month follow-up interview). Duration of breastfeeding was determined without consideration of whether or not mothers were combining bottle feeding with breastfeeding.

\section{Statistical Methods}

Initiation of breastfeeding

Initiation was defined as "ever breastfed." Potential predictors of initiation were identified using Students $t$-test for continuous variables and chi-square tests for categorical variables. Potential predictors considered were presence of a documented breastfeeding contraindication, maternal demographic factors, social and economic factors, presence of a supportive relative and/or friend (a relative/friend not living in the same household with whom they spoke every day or nearly everyday and in whom they felt they could confide) obstetrical factors, tobacco or alcohol use in pregnancy, whether the pregnancy was wanted or unwanted, mental and physical health status of mother, whether mother discussed her feeding method choice with a doctor or nurse since becoming pregnant, infant birth weight, and hospital of delivery. Variables associated with initiation of breastfeeding in unadjusted analysis $(p<0.2)$ were included in multivariable logistic regression models to determine whether these factors had independent predictive effects. A backward elimination approach was applied with hospital of delivery forced into all models. Maternal alcohol use was dropped from final models because it was not associated with breastfeeding initiation in multivariable analysis and because alcohol use was missing for a large fraction (12\%) of women. Most women in the study population were either nonHispanic African American or Hispanic Caucasian; therefore, only Hispanic ethnicity and not race was included in multivariable analysis. We ran additional models that included interaction terms for ethnicity by age and ethnicity by education because in previous studies the effects of age and education on breastfeeding practices have varied by ethnicity [20-22].

\section{Duration of breastfeeding}

We used Cox Proportional Hazards models [23] to identify factors significantly associated with duration of breastfeeding. Mothers who were still breastfeeding at the 7-12 month interview were censored, and the time to censoring was the time of the 7-12 month interview. The same variables that were considered as potential predictors of breastfeeding initiation were explored as potential predictors of continuation, and we again ran models that included interaction terms for ethnicity by age and ethnicity by education. Model adequacy checks were performed to ensure that assumptions for the proportions hazards models were satisfied.

All statistical tests were interpreted in a 2-tailed fashion to estimate $p$ values. The sample size was calculated to address determinants of immunization [18] and, thus, the 
Table I: Maternal and infant baseline characteristics

\begin{tabular}{|c|c|}
\hline Characteristic & $\begin{array}{c}\text { Study subjects }(\mathbf{N}=393) \\
\mathrm{n}(\%) *\end{array}$ \\
\hline \multicolumn{2}{|l|}{ Race/ethnicity } \\
\hline \multicolumn{2}{|l|}{ Hispanic } \\
\hline African American & $15(4 \%)$ \\
\hline Other & $52(13 \%)$ \\
\hline \multicolumn{2}{|l|}{ Non-Hispanic } \\
\hline African American & $318(81 \%)$ \\
\hline Other & $6(2 \%)$ \\
\hline \multicolumn{2}{|l|}{ Maternal age } \\
\hline$<20$ & $85(22 \%)$ \\
\hline$\geq 20$ & $308(78 \%)$ \\
\hline \multicolumn{2}{|l|}{ Marital status } \\
\hline Married/living with a partner & $108(27 \%)$ \\
\hline Single/no partner & $284(72 \%)$ \\
\hline \multicolumn{2}{|l|}{ Mother's birth place } \\
\hline USA & 309 (79\%) \\
\hline Other (foreign born) & $84(21 \%)$ \\
\hline \multicolumn{2}{|l|}{ Education } \\
\hline$<12$ years & I7I (44\%) \\
\hline$\geq 12$ years & 222 (56\%) \\
\hline \multicolumn{2}{|l|}{ Mother employed in past 12 months } \\
\hline Yes & 147 (37\%) \\
\hline No & 242 (62\%) \\
\hline \multicolumn{2}{|l|}{ Tobacco use during pregnancy } \\
\hline Yes & 87 (22\%) \\
\hline No & $274(70 \%)$ \\
\hline \multicolumn{2}{|l|}{ Poverty } \\
\hline Below poverty & $258(66 \%)$ \\
\hline At or above poverty & $117(30 \%)$ \\
\hline \multicolumn{2}{|l|}{ Previous live births } \\
\hline 0 & $134(34 \%)$ \\
\hline$\geq 1$ & $258(66 \%)$ \\
\hline \multicolumn{2}{|c|}{ Gestation at entry into prenatal care } \\
\hline$<4$ months & 255 (65\%) \\
\hline$\geq 4$ months & $138(35 \%)$ \\
\hline \multicolumn{2}{|l|}{ Infant birth weight } \\
\hline $1800-2499$ grams & $40(10 \%)$ \\
\hline$\geq 2500$ grams & $352(90 \%)$ \\
\hline \multicolumn{2}{|l|}{ Hospital of delivery } \\
\hline A & $106(27 \%)$ \\
\hline B & $86(22 \%)$ \\
\hline $\mathrm{C}$ & $20 \mathrm{I}(5 \mathrm{I} \%)$ \\
\hline
\end{tabular}

*Numbers may not add up to $100 \%$ because of missing values.

assumptions and differences are not relevant to the current study.

\section{Results}

\section{Study population}

Of the 1802 mothers delivering on the sampled days, 518 were eligible for enrollment in the study. The most common reasons for ineligibility were residency outside the District of Columbia, $(\mathrm{n}=704)$, being a private patient at site C ( $\mathrm{n}=373)$, and birth weight less than 1800 grams (
$=91)$. Four hundred fifty-two eligible mothers $(87 \%)$ gave informed consent and were successfully enrolled. Of these, 395 women $(87 \%)$ were successfully contacted for follow up at 3-7 months (and thus were interviewed about breastfeeding initiation) and 394 reported that they were still living with their infants since being discharged from the hospital. Information on breastfeeding initiation was missing for 1 woman, leaving 393 women for analysis of initiation rates. Three hundred sixty-nine women $(82 \%)$ were successfully contacted for an additional follow-up interview at 7-12 months. Characteristics of the study population are detailed in Table 1.

Based on information abstracted from medical records, women who were eligible but not enrolled or who were enrolled but later excluded from the analysis $(n=125)$ were slightly more likely to have had one or more previous live births or to have had a vaginal delivery than women included in the final analysis $(\mathrm{n}=393)(75 \%$ vs. $66 \%$ and $84 \%$ vs $77 \%$, respectively). The two groups were not markedly different, however, with respect to race, age, marital status, type of medical insurance, mother's employment status, WIC enrollment, birth weight, gestational age at delivery, infant sex, or delivery hospital.

\section{Initiation of breastfeeding}

Of the 393 women seen for the 3-7 month interview, 201 (51\%) initiated breastfeeding and 192 never breastfed. Sixty-one women ( $16 \%$ of the study population) had one or more documented contraindication to breastfeeding and of these, only 8 (13\%) initiated breastfeeding. In contrast, among the 332 women without contraindications, $193(58 \%)$ initiated breastfeeding. Of the 61 women with contraindications, $75 \%$ used cocaine, $28 \%$ had HIV infection, 5\% had tuberculosis, 5\% used PCP, and 3\% used heroin or methadone. Ninety-four percent of women with documented contraindications had either HIV infection, used cocaine, or both.

Breastfeeding initiation rates by potential predictors of interest are summarized in Table 2. In adjusted analysis, factors found to be independently associated with initiation of breastfeeding $(p<0.05)$ were mother foreign-born, supportive friend available (both positively associated); presence of a documented contraindication, maternal tobacco use, and supportive relative available (all negatively associated). The two factors most strongly associated with breastfeeding initiation were mother foreignborn (AOR, 4.90; 95\% CI, 2.38-10.10), and the presence of a documented contraindication (AOR, 0.19; 95\% CI, 0.08-0.47) (Table 3).

\section{Reasons for not breastfeeding}

Of the 192 women who never breastfed, the most common reasons reported for not breastfeeding were, "I did 
Table 2: Percent of women who initiated breastfeeding by baseline characteristics*

\begin{tabular}{|c|c|c|c|}
\hline Characteristic & $\mathbf{N} \dagger$ & $\begin{array}{l}\text { Percent who initiated } \\
\text { breastfeeding }\end{array}$ & $P \ddagger$ \\
\hline Total & 393 & $51 \%$ & \\
\hline \multicolumn{4}{|l|}{ Documented contraindication } \\
\hline Yes & 61 & $13 \%$ & $<0.0001$ \\
\hline No & 332 & $58 \%$ & \\
\hline \multicolumn{4}{|l|}{ Ethnicity } \\
\hline Hispanic & 68 & $81 \%$ & $<0.0001$ \\
\hline Non-Hispanic & 325 & $45 \%$ & \\
\hline \multicolumn{4}{|l|}{ Marital status } \\
\hline Married/living with a partner & 108 & $62 \%$ & 0.007 \\
\hline Single/no partner & 284 & $47 \%$ & \\
\hline \multicolumn{4}{|l|}{ Mother's birth place } \\
\hline United States & 309 & $42 \%$ & $<0.0001$ \\
\hline Other (foreign-born) & 84 & $85 \%$ & \\
\hline \multicolumn{4}{|l|}{ Mother employed in last 12 months } \\
\hline Yes & 147 & $56 \%$ & 0.09 \\
\hline No & 242 & $48 \%$ & \\
\hline \multicolumn{4}{|l|}{ Enrolled in WIC } \\
\hline Yes & 218 & $58 \%$ & 0.002 \\
\hline No & 175 & $42 \%$ & \\
\hline \multicolumn{4}{|l|}{ Grandmother living in the home } \\
\hline Yes & 110 & $43 \%$ & 0.04 \\
\hline No & 283 & $54 \%$ & \\
\hline \multicolumn{4}{|l|}{ Supportive relative available $\S$} \\
\hline Yes & 322 & $48 \%$ & 0.02 \\
\hline No & 71 & $63 \%$ & \\
\hline \multicolumn{4}{|l|}{ Supportive friend available $\S$} \\
\hline Yes & 288 & $55 \%$ & 0.03 \\
\hline No & 103 & $42 \%$ & \\
\hline \multicolumn{4}{|c|}{ Someone in the home with a drug problem } \\
\hline Yes & 22 & $27 \%$ & 0.02 \\
\hline No & 367 & $52 \%$ & \\
\hline \multicolumn{4}{|l|}{ Maternal tobacco use } \\
\hline Yes & 87 & $28 \%$ & $<0.0001$ \\
\hline No & 274 & $59 \%$ & \\
\hline \multicolumn{4}{|l|}{ Maternal alcohol use } \\
\hline Yes & 41 & $20 \%$ & $<0.0001$ \\
\hline No & 305 & $56 \%$ & \\
\hline \multicolumn{4}{|l|}{ Pregnancy wanted } \\
\hline Yes & 255 & $54 \%$ & 0.14 \\
\hline No & 133 & $46 \%$ & \\
\hline \multicolumn{4}{|l|}{ Mother depressed in the last year } \\
\hline Yes & 160 & $47 \%$ & 0.18 \\
\hline No & 229 & $54 \%$ & \\
\hline \multicolumn{4}{|c|}{$\begin{array}{l}\text { Mother with condition requiring medical } \\
\text { care }\end{array}$} \\
\hline Yes & 51 & $35 \%$ & 0.02 \\
\hline No & 342 & $54 \%$ & \\
\hline \multicolumn{4}{|l|}{ Number of previous live births } \\
\hline None & 134 & $58 \%$ & 0.05 \\
\hline One or more & 258 & $48 \%$ & \\
\hline \multicolumn{4}{|c|}{ Gestation at entry into prenatal care } \\
\hline$\leq 4$ months & 255 & $56 \%$ & 0.01 \\
\hline$>4$ months & 138 & $43 \%$ & \\
\hline \multicolumn{4}{|l|}{ Mode of delivery } \\
\hline Vaginal & 299 & $49 \%$ & 0.08 \\
\hline
\end{tabular}


Table 2: Percent of women who initiated breastfeeding by baseline characteristics* (Continued)

\begin{tabular}{lccc}
\hline Cesarean section & 89 & $60 \%$ & 0.07 \\
Infant birth weight & 40 & $38 \%$ & \\
$<2500$ grams & 352 & $53 \%$ & 0.14 \\
$\geq 2500$ grams & 106 & $50 \%$ & \\
Hospital of delivery & 86 & $60 \%$ & \\
A & 201 & $48 \%$ & \\
B & & & \\
C &
\end{tabular}

*Baseline variables not associated with initiation of breastfeeding $(P>0.2)$ included maternal years of education, whether mother was above poverty level, whether mother or infant ever threatened, and whether mother discussed feeding method choice with a doctor or nurse during pregnancy. †Numbers may not add up to 393 due to missing data. $\ddagger P$-values computed using chi-square tests. $§ S t u d y$ subjects were asked in they had a relative/friend not living in the same household with whom they spoke every day or nearly everyday and in whom they felt they could confide.

Table 3: Predictors of initiation and duration of breastfeeding, adjusted analysis

\begin{tabular}{lcc}
\hline Predictors of initiation $(\mathrm{N}=393)^{*}$ & Adjusted odds ratio & 95\% Confidence interval \\
\hline Mother foreign-born & 4.90 & $2.38-10.10$ \\
Supportive friend available & 2.27 & $1.26-4.09$ \\
Contraindication to breastfeeding & 0.19 & $0.08-0.47$ \\
Mother used tobacco & 0.52 & $0.28-0.98$ \\
Supportive relative available & 0.46 & $0.23-0.92$ \\
\hline Predictors of breastfeeding & Hazards ratioł§ & $\mathbf{9 5 \%}$ Confidence interval \\
discontinuation & & \\
N 198$) \ddagger$ & & $0.39-0.77$ \\
\hline Mother foreign-born & 0.55 & $0.69-0.92$ \\
Maternal age (5-year increments) & 0.80 & $0.26-0.80$ \\
Birth weight $\geq 2500$ grams & 0.45 &
\end{tabular}

*Complete data available for 342 women who were included in final models. †Delivery hospital was forced into all models but did not contribute significantly. $¥$ Complete data available for 190 women who were included in final models. §Hazard ratio represents the hazard for discontinuing breastfeeding; a value $<I$ indicates a decreased risk of discontinuation.

not want to" (48\%), "I didn't want to pass dangerous things" (25\%), and "Other reason" (11\%). Less common were "Nipple and/or breast problems" (9\%), "Schedule difficult" (4\%), "I was ill/weak" (4\%), "Baby refused" (3\%), "I produced insufficient milk" (3\%), "Baby was ill/ weak" (1\%), or "I was never taught" (1\%).

Of the 48 women who didn't breastfeed because they "did not want to pass dangerous things," only 22 (46\%) had a documented contraindication to breastfeeding. Conversely, of the 53 women with a documented breastfeeding contraindication who did not breastfeed, 22 (42\%) reported that they "did not want to pass dangerous things." In all, 87 women (22\% of those seen for 3-7 month follow-up) had a documented and/or perceived breastfeeding contraindication, and of the 192 women who did not breastfeed, $41 \%$ had a documented and/or perceived contraindication.

\section{Duration of breastfeeding}

Out of 201 women who initiated breastfeeding, 3 had incomplete follow-up information. Of the remaining 198 women, $77 \%$ had quit breastfeeding by the 3-7 month follow-up interview and $91 \%$ had quit by the $7-12$ month follow-up interview. Twenty-one percent of initiators quit in the first 2 weeks, 30 percent between 2 weeks and 2 months, 28 percent between 2 months and 4 months, and 21 percent breastfed 4 months or more.

Factors potentially associated with discontinuation of breastfeeding $(p<0.20)$ were identified in unadjusted survival analysis. Potentially protective factors identified included increasing maternal age, Hispanic ethnicity, high school education or greater, mother employed in the last 12 months, married or with a partner, one or more previous live births, vaginal delivery, pregnancy wanted, mother foreign-born, and infant birth weight $\geq 2500$ 
Table 4: Most frequently reported reasons for breastfeeding discontinuation by duration of breastfeeding among women who initiated breastfeeding $(\mathbf{N}=181)^{*}$

\begin{tabular}{|c|c|c|c|c|c|c|c|c|}
\hline \multirow[b]{2}{*}{ Reason $†$} & \multicolumn{2}{|c|}{$\begin{array}{c}<2 \text { weeks } \\
(n=41)\end{array}$} & \multicolumn{2}{|c|}{$\begin{array}{l}2 \text { weeks-2 months } \\
(n=59)\end{array}$} & \multicolumn{2}{|c|}{$\begin{array}{l}2-4 \text { months } \\
(n=56)\end{array}$} & \multicolumn{2}{|c|}{$\begin{array}{c}>4 \text { months } \\
(n=25)\end{array}$} \\
\hline & $\underline{N}$ & \%‡ & $\underline{N}$ & $\underline{\% \neq}$ & $\underline{N}$ & $\underline{\% \neq}$ & $\underline{N}$ & \%‡ \\
\hline Nipple/breast problems & 13 & $32 \%$ & II & $19 \%$ & 6 & $11 \%$ & 0 & $0 \%$ \\
\hline Insufficient milk & 5 & $12 \%$ & 15 & $25 \%$ & 15 & $27 \%$ & 6 & $24 \%$ \\
\hline Schedule difficult & 2 & $5 \%$ & 10 & $17 \%$ & 9 & $16 \%$ & 8 & $32 \%$ \\
\hline Baby refused & 7 & $17 \%$ & 15 & $25 \%$ & 17 & $30 \%$ & 4 & $16 \%$ \\
\hline Did not want to & 7 & $17 \%$ & 2 & $3 \%$ & 0 & $0 \%$ & 3 & $12 \%$ \\
\hline Other & 10 & $24 \%$ & 10 & $17 \%$ & 12 & $21 \%$ & 6 & $24 \%$ \\
\hline
\end{tabular}

*A total of 201 women breastfeed, but the reason for discontinuation was missing for 3 women and unknown for 17 women still breastfeeding at the end of the study. †Reasons infrequently reported in all groups were "I (mother) was ill/weak," "baby was ill/weak," "I didn't want to pass dangerous things through breastmilk," and "I was never taught or didn't know how." $\ddagger$ Percentages may exceed $100 \%$ because some women listed multiple reasons for not breastfeeding and because of rounding.

grams; potential risk factors included presence of a documented contraindication, feeding choice discussed with a doctor or nurse, a grandmother living in the home, and supportive relative available. In adjusted analyses, factors independently associated with discontinuation of breastfeeding $(p<0.05)$ were mother foreign-born, increasing maternal age, and infant birth weight $\geq 2500$ grams (all were protective against discontinuation) (Table 3). Presence of a contraindication was not associated with continuation in adjusted analysis. We found no significant interaction between age and ethnicity or between education and ethnicity.

\section{Reasons for discontinuation}

Information on why women stopped breastfeeding was available for 181 of the 201 women who initiated breastfeeding (the reason for stopping was unknown for the 17 women who were still breastfeeding at the second followup and for the 3 women whose follow-up information was incomplete). The most frequently reported reasons for discontinuing were "Baby refused" (24\%), "I produced insufficient milk" (23\%), "Other reason" (21\%) "Nipple and/or breast problems" (17\%), and "Schedule difficult" (16\%). Less common were, "I didn't want to" (7\%), "I was ill/weak" (3\%), "I didn't want to pass dangerous things" $(4 \%)$, or "I was never taught" $(0 \%)$. Reasons for discontinuation varied by duration of breastfeeding. Among women who breastfed less than 2 weeks, "Nipple and/or breast problems" was the most common reason cited, while among women who breastfed 4 months or more, "Schedule difficult"was most common (Table 4).

\section{Discussion}

In many communities in the United States it has been difficult to achieve high rates of breastfeeding initiation. Reasons for this are complex, and it is likely that multiple forces involving the mother, the infant, and the environ- ment interact to influence infant feeding-method decisions. In our study population of low-income, inner city women, we found that the rate of breastfeeding initiation was 51\%, well below the Healthy People 2010 goal of $75 \%$, and that $79 \%$ of women who initiated breastfeeding had discontinued by 4 months. We also found that contraindications to breastfeeding and concern about "passing dangerous things" were common. In all, $22 \%$ of our study population had a documented contraindication to breastfeeding or did not initiate breastfeeding because of concern about passing dangerous things to their infants through breast milk. Of women who did not breastfeed, $41 \%$ had a documented and/or a perceived contraindication to breastfeeding. Thus, breastfeeding contraindications played an important role in infant feeding method decisions in our population.

\section{Previous studies}

The rate of breastfeeding initiation in our study (51\%) was slightly lower than rates described in two recently published reports that were drawn from populationbased samples of women living in the United States. The breastfeeding initiation rates reported in these studies were 57\% for 1993 [24] and for 1995 [12]. We did not observe significant associations between breastfeeding and several factors previously reported to be predictive of breastfeeding initiation and/or duration, such as maternal ethnicity, education, socioeconomic status, employment status, marital status, parity, and type of delivery $[12,13,25]$. This may reflect our economically homogeneous study group. We did find a strong association between breastfeeding initiation and maternal foreign-birth, and between breastfeeding duration and maternal age, foreign-birth, and infant birth weight, which have been previously described [26-32]. The association between maternal foreign birth and breastfeeding initiation and breastfeeding duration underscores the importance of cul- 
tural forces in infant feeding method-decisions. Interestingly, we also noted a negative association between breastfeeding initiation and the availability of a supportive relative and a positive association with the availability of a supportive friend. It may be that relatives discourage breastfeeding while friends are more encouraging. The attitude toward breastfeeding of the father or partner, which has been found to play an important role in infant feeding decisions [33], was not evaluated in this study.

The most common reason reported for not breastfeeding was "I didn't want to." This finding is consistent with a recently published study of breastfeeding initiation in which, in a national sample of women, the most common reason reported for not breastfeeding was "preferred to bottle feed" [12]. However, in our study, the second-most common reason women reported for not breastfeeding was "I didn't want to pass dangerous things." In this highrisk population, "concern about passing dangerous things" appears to have played an important role in infant feeding method decisions.

It is not clear why some women with contraindications to breastfeeding did not express concern about passing dangerous things through breast milk when asked why they chose not to breastfeed. It is possible that these women had other more pressing obstacles to breastfeeding or that they were unaware that breastfeeding was contraindicated. Alternatively, in some cases the contraindication may have been resolved by the time of delivery.

Breastfeeding drop-off rates were high in our study-only $49 \%$ of women who initiated breastfeeding continued 2 months or more and only $21 \%$ continued 4 months or more. This is in contrast to the finding that $57 \%$ of initiators breastfeed 10 or more weeks in a population-based sample of women [24]. Barriers to continued breastfeeding identified in our study included baby's refusal, a perception of insufficient milk production, and nipple and/ or breast problems, which is also consistent with previous studies $[29,34,35]$. Contrary to what we observed in our analysis of breastfeeding initiation, we did not find that concern about passing dangerous things was important in decisions to discontinue breastfeeding.

Little is known about how women's perceptions of contraindications such as the use of certain medications and the presence of illness in the mother or infant influence infant feeding method decisions. In our study, we could find no documentation of any breastfeeding contraindications in over half of the women who reported that they didn't breastfeed because they "did not want to pass dangerous things." While these women may have had true (but undocumented) breastfeeding contraindication, this finding raises the possibility that misperceptions regard- ing breastfeeding contraindications may have contributed to low breastfeeding initiation rates in our study population. Additional studies are needed to determine to what extent misperceptions regarding breastfeeding contraindications contribute to infant feeding method decisions.

\section{Methodologic considerations}

The primary strengths of this cohort study are the inclusion of information on breastfeeding contraindications and maternal perceptions of contraindications, detailed information on other potential risk factors for not breastfeeding, and estimates of duration of breastfeeding. Perhaps the most important limitation is its generalizability. Although women were selected to represent District of Columbia residents of lower socioecomonic status, our sampling scheme was not population-based. Because the prevalence of contraindications to breastfeeding such as HIV infection and substance abuse can vary widely between communities, our findings likely have the most relevance for high-risk communities. An additional limitation is that estimates of duration of breastfeeding were obtained retrospectively from interviews conducted at 37 months and 7-12 months postpartum, and so mothers may not have reported breastfeeding duration accurately. Finally, women in our study who did initiate breastfeeding were not asked if they were concerned about "passing dangerous things." Therefore, we were not able to directly evaluate the role of perceived contraindications as a predictor of breastfeeding practices.

\section{Conclusions}

Successful breastfeeding requires healthy mother-infant pairs. Reducing health burdens brought on by HIV infection and substance abuse is an important step toward achieving Healthy People 2010 breastfeeding goals. It is important to consider the prevalence of contraindications when evaluating breastfeeding practices in high risk communities.

\section{List Of Abbreviations}

$\mathrm{AOR}=$ adjusted odds ratio; $\mathrm{OR}=$ odds ratio; $\mathrm{CI}=$ confidence interval

\section{Competing Interests}

None declared.

\section{Authors' Contributions}

Lucinda England and Ruth Brenner conceived of the current study hypothesis. Lucinda England supervised the analysis and led the writing of the manuscript. Ruth Brenner, Bruce Simons-Morton, and John Clemens conceptualized the original study, developed the methods and managed the implementation. Ruth Brenner supervised the writing of the manuscript. Brinda Bhaskar conducted the analysis. Abhik Das provided statistical guidance. 
Mary Revenis and Nitin Mehta assisted with study design. All authors helped to interpret the findings and reviewed drafts of the manuscript.

\section{Acknowledgements}

This work was supported in part by grants UI8-HD30447, UI8-HD30458, UI8-HD30450, UI8-HD30445, UI8-HD31919, UI8-HD30454, and UI8HD3 206 from the National Institute of Child Health and Human Development and the National Institutes of Health, Office of Research in Minority Health, Bethesda, Md.

This study was part of National Institutes of Health's Initiative to Reduce Infant Mortality in Minority Populations in the District of Columbia. The following institutions participated in this initiative: The Children's National Medical Center, Washington, DC; the Washington, DC, Department of Public Health; Washington, DC, General Hospital; Georgetown University Medical Center; Howard University, Washington, DC; and the University of the District of Columbia, Washington, DC; The Research Triangle Institute, Rockville, Md; and the National Institute of Child Health and Human Development, Bethesda, Md. The Washington Hospital Center, Washington, DC, also participated in this study.

\section{References}

I. Dewey KG, Heinig MJ and Nommsen-Rivers LA: Differences in morbidity between breast-fed and formula-fed infants. J Pediatr 1995, I 26:696-702.

2. Howie PW, Forsyth JS, Ogston SA, Clark A and Florey CD: Protective effect of breast feeding against infection. BMJ 1990 , 300: $11-16$.

3. Kovar MG, Serdula MK, Marks JS and Fraser DW: Review of the epidemiologic evidence for an association between infant feeding and infant health. Pediatrics 1984, 74:6 I 5-638.

4. Beaudry M, Dufour $R$ and Marcoux S: Relation between infant feeding and infections during the first six months of life. J Pediatr 1995, I 26:191-197.

5. Frank AL, Taber LH, Glezen WP, Kasel GL, Wells CR and Paredes A: Breast-feeding and respiratory virus infection. Pediatrics 1982 , 70:239-245

6. Mayer EJ, Hamman RF, Gay EC, Lezotte DC, Savitz DA and Klingensmith GJ: Reduced risk of IDDM among breast-fed children. Diabetes 1988, 37:1625-1632.

7. Rigas A, Rigas B, Glassman M, Yen YY, Lan SJ, Petridon E, Hsieh CC and Trichopoulos D: Breast-feeding and maternal smoking in the etiology of Crohn's disease and ulcerative colitis in childhood. Ann Epidemiol 1993, 3:387-392.

8. Davis MK, Savitz DA and Graubard BI: Infant feeding and childhood cancer. Lancet 1988, 2:365-368.

9. Angelsen NK, Vik T, Jacobsen G and Bakketeig LS: Breast feeding and cognitive development at age $I$ and 5 years. Arch Dis Child 200I, 85: $183-188$

10. American Academy of Pediatrics, Work Group on Breastfeeding: Breastfeeding and the use of human milk. Pediatrics 1997, 100:1035-1039.

II. U.S. Department of Health and Human Services: Healthy People 20 I 0: Understanding and Improving Health. U.S. Government Printing Office 22000.

12. Forste R, Weiss J and Lippincott $\mathrm{E}$ : The decision to breastfeed in the United States: does race matter? Pediatrics 2001, I 08:29|-296.

13. Wiemann CM, DuBois JC and Berenson AB: Racial/ethnic differences in the decision to breastfeed among adolescent mothers. Pediatrics 1998, I0 I:EII.

14. Ryan AS: The resurgence of breastfeeding in the United States. Pediatrics 1997, 99:EI2.

15. American Academy of Pediatrics: Human Milk. In 2000 Red Book: Report of the Committee on Infectious Diseases 25th edition. Edited by: Pickering LK. Elk Grove Village, IL: American Academy of Pediatrics; 2000:98-104
16. Lawrence RM and Lawrence RA: Given the benefits of breastfeeding, what contraindications exist? Pediatr Clin North Am 200I, 48:235-25I.

17. American Academy of Pediatrics Committee on Drugs: The transfer of drugs and other chemicals into human milk. Pediatrics 200I, I 08:776-789.

18. Brenner RA, Simons-Morton BG, Bhaskar B, Das A and Clemens JD: Prevalence and predictors of immunization among innercity infants: a birth cohort study. Pediatrics 200I, I 08:66 I-670.

19. Kelly JE, Mosher WD, Differ AP and Kinsey SH: Plan and operation of the 1995 National Survey of Family Growth. Vital Health Stat 1997, I(36):.

20. Rassin DK, Markides KS, Baranowski T, Richardson CJ, Mikrut WD and Bee DE: Acculturation and breastfeeding on the United States-Mexico border. Am J Med Sci 1993, 306:28-34.

21. Wright AL, Holberg $C$ and Taussig LM: Infant-feeding practices among middle-class Anglos and Hispanics. Pediatrics 1988 82:496-503.

22. Bee DE, Baranowski T, Rassin DK, Richardson CJ and Mikrut WD: Breast-feeding initiation in a triethnic population. Am J Dis Child 1991, 145:306-309.

23. Hosmer DW and Lemeshow S: Applied Survival Analysis: Regression Modeling of Time to Event Data. New York, New York: John Wiley \& Sons, Inc 1999.

24. Ahluwlia IB, Morrow B, Hsia J and Grummer-Strawn LM: Who is breastfeeding? Recent trends from the pregnancy risk assessment and monitoring system. J Pediatr 2003, I 42:486-9I.

25. Scott JA and Binns CW: Factors associated with the initiation and duration of breastfeeding: a review of the literature. Breastfeed Rev 1999, 7:5-16.

26. Romero-Gwynn E and Carias L: Breast-feeding intentions and practice among Hispanic mothers in southern California. Pediatrics 1989, 84:626-632.

27. Rassin DK, Markides KS, Baranowski T, Richardson CJ, Mikrut WD and Bee DE: Acculturation and the initiation of breastfeeding. J Clin Epidemiol 1994, 47:739-746.

28. Byrd TL, Balcazar $\mathrm{H}$ and Hummer RA: Acculturation and breastfeeding intention and practice in Hispanic women on the USMexico border. Ethn Dis 200 I, I I:72-79.

29. Ertem IO, Votto $\mathrm{N}$ and Leventhal JM: The timing and predictors of the early termination of breastfeeding. Pediatrics 200I, I 07:543-548.

30. Pande $\mathrm{H}$, Unwin $\mathrm{C}$ and Haheim LL: Factors associated with the duration of breastfeeding: analysis of the primary and secondary responders to a self-completed questionnaire. Acto Paediatr 1997, 86: 173-177.

31. Lefebvre $F$ and Ducharme $M$ : Incidence and duration of lactation and lactational performance among mothers of low-birthweight and term infants. CMAJ 1989, I40: I I59-I I64.

32. John AM and Martorell R: Incidence and duration of breast-feeding in Mexican-American infants, 1970-1982. Am J Clin Nutr 1989, 50:868-874.

33. Bar-Yam N. and Darby L: Fathers and breastfeeding: A review of the literature. J Hum Lact 1997, I 3:45-50.

34. Novotny R, Hla MM, Kieffer EC, Park CB, Mor J and Thiele M: Breastfeeding duration in a multiethnic population in Hawaii. Birth 2000, 27:91-96.

35. Whichelow MJ: Factors associated with the duration of breast feeding in a privileged society. Early Hum Dev 1982, 7:273-280.

\section{Pre-publication history}

The pre-publication history for this paper can be accessed here:

http://www.biomedcentral.com/1471-2458/3/28/prepub 